\title{
Mewujudkan Citra Pemimpin Abad Ke-21 Bertolak Pada Ajaran Astha Brata Untuk Masa Depan Kabupaten Nganjuk
}

\section{Siti Musa'adah, Akhmad Arif Musadad, Sudiyanto}

Universitas Sebelas Maret

sitimusaadah191@student.uns.ac.id

\section{Article History}

received $1 / 9 / 2021$

revised $1 / 10 / 2021$

accepted $1 / 11 / 2021$

\begin{abstract}
The purpose of this study is to find out and examine the existing leadership Nganjuk Regency, as for the formulation of the problem to be discussed, namely 1) what is the defenition of leadership?, 2) how is the concept of Astha Brata teachings?, 3) how is the image of the Nganjuk Regent's leadership based on Astha Brata teachings?, research using a qualitative methodology with a literature study appoach. The findings show that leaders in Nganjuk Regency don't yet have and apply the leadership attitudes that exist in the teaching of the Astha Brata, leaders often abuse power, to improve the image of the Nganjuk leadershio, it is necessary to reorganize so that the same case does'nt happen again.
\end{abstract}

Keywords: Leadership, 21st Century, Nganjuk Regency

\begin{abstract}
Abstrak
Pemimpin Tujuan penelitian ini untuk mengetahui dan mengkaji kepemimpinan yang ada di Kabupaten Nganjuk, adapun rumusan masalah yang akan dibahas yaitu 1) bagaimana definisi tentang kepemimpinan?, 2) bagaimana konsep ajaran Astha Brata?, 3) bagaimana citra kepemimpinan Bupati Nganjuk bertolak pada Ajaran Astha Brata?, menggunakan metodologi kualitatif dengan pendekatan studi pustaka. Hasil penemuan menunjukkan pemimpin di Kabupaten Nganjuk belum mempunyai dan menerapkan sikap kepemimpinan yang ada di ajaran Astha Brata, para pemimpin sering melakukan penyelewengan kekuasaan, untuk memperbaiki citra kepimpin Kabupaten Nganjuk perlu diadakan reorganisasi agar kasus yang sama tidak kembali terulang.
\end{abstract}

Kata kunci: Kepimimpinan, Abad ke-21, Kabupaten Nganjuk

Social, Humanities, and Education Studies (SHEs): Conference Series https://jurnal.uns.ac.id/shes 


\section{PENDAHULUAN}

Kepemimpinan Mantan wakil presiden Indonesia Mohammad Hatta pernah berkata bahwa "korupsi telah membudaya di Indonesia (Indonesia Observer, 2 Juli 1970), hal ini menunjukkan bahwa Indonesia memiliki repitasi sebagai negara korup jauh dengan menempatan masyarakat Internasional bahwa Indonesia sebagai negara terkorup (Margana, 2017: 105). Pada masyarakat Jawa tidak bisa dipungkiri bahwa budaya korupsi atau memberi imbalan bukan pada tempatnya sudah menjadi budaya orang Jawa. Menurut Pater Carey orang Jawa sering menerima imbalan atas jasa yang diberikan oleh orang lain (Carey, 2017: xxii). Mungkin dalam konteks kekeluargaan hal ini masih dikatakan wajar, namun apabila dibawa keranah politik hal tersebut pasti bertentangan pada undang-undang yang berlaku.

Masa depan suatu daerah dibangun atas dasar kemauan dan kerjasama yang solid, Nganjuk merupakan salah satu daerah yang ada di Provinsi Jawa Timur, dalam sejarahnya Nganjuk dikenal dengan Anjuk Ladang mempunyai arti tanah kemenangan, dibangun pada tahun 859 Çaka atau 937 Masehi. Berdasarkan peta Jawa Tengah dan Jawa Timur pada diawal tahun 1811 wilayah Nganjuk terbagi dalam 4 daerah yaitu Berbek, Godean, Nganjuk dan Kertosono.

Seringkali pembahasan mengenai Nganjuk bukan karena prestasinya tetapi lebih pada bahasan kasus korupsi, banyak penyelewengan penyalahgunaan jabatan yang terjadi di Kabupaten Nganjuk. Penelitian ini bertujuan untuk menganalisis bentuk penyelewengan penyalahgunaan jabatan yang banyak terjadi pada pejabat Kabupateng Nganjuk, dengan menggunakan studi pustaka peneliti akan menganalisis dengan beberapa referensi buku dan artikel ilmiah.

Berdasarkan uraian di atas maka rumusan masalah yang akan dibahas, 1) bagaimana definisi tentang kepemimpinan?, 2) bagaimana konsep ajaran Astha Brata?, 3) bagaimana citra kepemimpinan Bupati Nganjuk bertolak pada Ajaran Astha Brata? Dan tujuan penelitian ini yaitu 1) mengetahui definisi tentang kepemimpinan, 2) mengetahui konsep ajaran Astha Brata, 3) mengetahui citra kepemimpinan Bupati Nganjuk bertolak pada Ajaran Astha Brata.

\section{Teori Kepemimpinan}

\section{TEORI DAN METODE}

Pemimpin dan kepemimpinan dapat didefinisikan berdasarkan pendekatannya antara lain sebagai berikut (1) pendekatan berdasarkan karakteristik pribadi, pendekatan ini melihat pemimpin adalah seorang yang mampu memimpin dilihat sejak sebelum lahir sampai sesudah lahir, pendekatan ini juga menekankan pada karakteristik kepribadian pemimpin, (2) pendekatan berdasarkan perilaku atau disebut dengan pendekatan behavioral atau environmental, pendekatan ini berfokus pada aspek psikologi kepemimpinan kelomok, (3) pendekatan berdasarkan pengaruh kekuasaan-pengaruh, pendekatan ini disebut juga dengan pendekatan kepemimpinan karismati, di mana seoarang pemimpin akan dilihat pengaruhkan terhadap kelompok, (4) pendekatan berdasarkan situasional atau kepemimpinan kontinjensi, artinya melihat kontekstual yang dihadapi pemimpin dalam organisasi seperti tuntutan pekerjaan, sifat pekerjaan, dan hubungan atasan terhadap bawahannya.

Salah satu pendekata yang aka dibahas yaitu pendekatan perilaku kepemimpinan, pendekatan ini dibagi ke dalam lima macam yaitu (1) teori peran atau role theory, (2). consideration vs initiating structure theory dari universitas Ohio, (3) teori dari universitas Michigan, (4) teori kisi-kisi manajerial atau manajerial grid, dan (5) teori $X$ dan $Y$ dari Mc Gregor (Haryono,2015:29). Teori perilaku mengasumsikan kemimpinan dapat dipelajari seseorang bukan hanya karena garis keturunan tetapi dipelajari berdasarkan konsepnya, sejumlah penelitian menjelaskan bahwa perilaku baik akan menghasilkan kepemimpinan yang baik pula (Chabiago, 2017:30). 
Definisi kepemimpinan, dalam bahasa Inggris kata kepemimpinan berasal dari kata Leadership dan pada bahasa Arab Zi'amah atau Imamah, kemudian dalam terminologi kepemimpinan adalah suatu yang berhubungan dengan stimulus, mobilisasi, pengkoordinasian, pengarahan, dan motif-motif yang meilibatkan orang banyak (Hamzah, 125). Beberapa tokoh penguraikan pengertian sikap kepemimpinan sebagai berikut:

a. George R. Terry (1984) kepemimpinan adalah kegiatan mempengaruhi orang-orang untuk mencapai tujuan bersama.

b. Kootz \& O'donnel (1984) kepemimpinan dalah proses mempengaruhi kelompok-kelompok sehingga mau bekerjasama mencapai sebuh tujuan.

c. J. M P Fifner kepemimpinan adalah seni mengkoordinasi dan mengarahkan individu atau kelompok untuk mencapai tujuan bersama (Fifner dalam Gary, 2011: 4).

d. Mangunharja mendefinisikan kepemimpinan mengandung arti bergerak lebih awal, berjalan ke depan, mengambil langkah paling utama, berbuat secara cepat, membimbing, dan menuntun anggota ke arah tujuan yang sama (Mangunharja dalam Efendi, 2014: 343).

Jadi dari pengertian tersebut dapat diambil simpulan bahwa kepemimpinan merupakan kemampuan dan kesiapan yang dimiliki individu untuk mempengaruhi, mendorong, mengajak, menuntun, menggerakkan, dan jika diperlukan memaksa orang lain agar dia mengikuti arahan kita yang kemudian akan membantu tercapainya sebuah tujuan yang dimaksud.

Prinsip-prinsip kepemimpinan terbagi menjadi dua yaitu prinsip umum dan prinsip khusus (Jawa). Prinsip umum dalam berorganisasi terdiri dari enam yaitu:

a. Mengadakan pembaruan secara berkala, artinya pemimpin mengadakan kegiatan yang dapat memotivasi dan memberikan inovasi baru,

b. Mengakui masalah secara terbuka. Keterbukaan sebagai kekuatan yang bisa mengendalikan dan mengatasi berbagai masalah dengan cepat, dan juga sama secepatnya dapat mewujudkan kemampuan.

c. Mempromosikan keterbukaan, bagi organisasi tradisional, ilmu pengetahuan adalah kekuasaan pribadi. Tetapi bagi organisasi kaizen, ilmu adalah untuk saling dibagikan dan hubungan komunikasi yang mendukungnya adalah sumber efisiensi yang besar.

d. Menciptakan tim kerja. Dalam organisasi Kaizen tim adalah bahan bangunan dasar yang membentuk struktur organisasi. Masing-masing karyawan secara individual memberikan sumbangan berupa reputasi akan efisiensi, prestasi kerja dan peningkatannya.

e. Memberikan proses hubungan kerja yang benar. Dalam organisasi kaizen tidak menyukai hubungan yang saling bermusuhan dan penuh kontroversi yang terjadi dalam perusahaan secara murni berpusat pada hal-hal yang memiliki kultur yang saling menyalahkan.

f. Mengembangkan disiplin pribadi. Disiplin di tempat kerja merupakan sifat alamiah dan menuntut pengorbanan pribadi untuk menciptakan suasana harmonis dengan rekan sekerja di dalam tim dan prinsipprinsip utama perusahaan, sehingga sifat-sifat individual yang terpenting bisa tetap terjaga (Nasharuddin, 2014: 127).

Sedangkan prinsip Jawa sebagai komunitas terbesar di Indonesia juga mempunyai prinsip sendiri yang dimanakan kredo, kinerja orang Jawa dipengaruhi oleh peran pemimpin. Pemimpin adalah motor penggerak sebuah komunitas, apabila menginginkan kesinambungan dalam tumbuh kembangnya organisasi di masa depan, pemimpin harus dipersiapkan lebih awal. Bagaimana mengidentifikasi ciri-ciri pemimpin sejati, memang tidak mudah. Sudah lama terjadi perdebatan tentang proses seseorang menjadi pemimpin (leader) dalam masyarakat Jawa. Ada kalanya masyarakat 
membedakan mana pemimpin ala Jawa, Sunda, Minang, Bugis, dan sebagainya. Etnisitas masih sering mewarnai ala kepemimpinan, baik kepemimpinan local maupun nasional. Tiga pokok dari sifat pemimpin yang kerap dibutuhkan oleh suatu kelompok atau organisasi yaitu (1) berada di depan, (2) mengayomi, dan (3) mencerahkan. Ketiga sifat kepemimpinan tersebut merupakan syarat yang menentukan keberhasilan suatu komunitas. Pemimpin yang berani di depan, memberikan tauladan, tergolong mulia. Sebaliknya, manakala pemimpin hanya bertindak seperti ungkapan "wit gedhang awoh pakel", artinya omong gampang nglakoni angel, kepercayaan rakyat akan semakin pudar. Begitu pula ungkapan "gajah diblangkoni, bisa kojah ora bisa nglakoni, artinya pemimpin hanya banyak bicara, realisasinya nol, akan dicemooh oleh bawahan (Endraswara, 2013: 46)

\section{METODE}

Jenis penelitian ini adalah penelitian kualitatif dengan menggunakan studi pustaka di mana peneliti menggunakan sumber data berupa buku-buku referensi dan artikel-artikel jurnal ilmiah. Adapun prosedur pada penelitian studi pustaka meliputi a) melihat ide umum tentang penelitian, b) mencari informasi yang mendukung penelitian, c) mempertegas fokus penelitian dan mengorganisasi bahan yang sesuai, d) mencari dan menemukan sumber data berupa sumber pustaka utama yaitu buku dan jurnal ilmiah, e) melakukan re-organisasi bahan dan catatan simpulan yang didapat dari sumber data, f) melakukan review mengenai informasi yang telah dianalisis dan sesuai untuk membahas dan menjawab rumusan masalah, g) memperkaya sumber data untuk menganalisis, h) menyusun hasil penelitian.

\section{HASIL DAN PEMBAHASAN}

Pemimpin Salah satu konsep kepemimpinan Jawa diperoleh dari masa HinduBudha di Indonesia, dimana ajaran Astha Brata bermula saat tokoh Rama dalam cerita Ramayana ingin memberikan petuah pada adik kandung Rahwana sebagai pengganti negeri Alengka bernama Wibisana. Cerita Ramayana dalam kutipan Zoelmunder (1974: 282-286) terdapat beberapa bagian cerita Ramayana berdasarkan pupuh Ramayana antara lain:

Pupuh 8 (1-214): menjelaskan bahwa Hanuman utusan Rama tiba di negeri Langka untuk mencari keberadaan Dewi Sita, kemudian Hanuman memberikan cincin dan surat dari Rama kepada Dewi Sita, dan Dewi Sitapun membalas dengan hal serupa dititipkan kepada Hanuman.

Pupuh 11 (1-96): Hanuman ekornya dibakar oleh Indrajit karena telah membunuh Aksa dan merusak tanaman yang ada di taman Langka, ekornya terbakar dan Hanuman melarikan diri melompat rumah-rumah warga. Negeri Langkapun juga ikut hangus terbakar.

Pupuh 16 (1-47): Rama menyuruh semua kera membuat Tamwak (tambak atau bendungan) sebagai akses jalan menuju ke Langka

Pupuh 20 (1-80): sesampainya di Langka pasukan Rama yaitu para kera dan pasukan Rahwana yaitu raksasa bertempur di medan perang.

pupuh 23 (1-85) diakhir cerita Kumbakarna patih Rahwana tewas di tangan Rama dan Laksmana.

Cerita Ramayana dapat dilihat pada relief Candi Prambanan dan Candi Panataran secara garis besar kedua relief tersebut mempunyai alur cerita yang berbeda. Cerita Ramayana pada Candi Prambanan diawali dari Candi Siwa dengan 
cerita dimulai saat penitisan Wisnu sampai Rama menyebrang lautan, kemudian cerita dilanjut pada dinding Candi Brahma dengan cerita Rama sampai ke Langka (Wirjomartono, 2009:196-197). Sementara cerita Ramayana di kompleks Candi Panataran terletak di dinding candi induk, cerita diawali dari kedatangan Hanuman sebagai utusan Rama ke Langka, Hanuman mempunyai tugas memberi cincin dari Rama kepada Dewi Sita, dalam perjalanannya banyak pengawal istana yang mengetahui Hanuman, sampai Hanuman dikepung dan dibakar hidup-hidup, namun Hanuman tidak mati. Cerita berakhir ketika Rama dan pasukan kera datang ke Langka dan menyerbu istana Rahwana, semua penduduk istana mati dan satu-satunya yang dapat membantu Rahwana adalah Kumbakarna, namun Kumbakarna juga mati di tangan Rama dan Laksmana (Ngadiono dkk, 2003:54-58).

Perbedaan lain dari segi pemahatan relief, cerita Ramayana di Candi Prambanan dipahat pada pagar langkan, sedangkan di Candi Panataran dipahat pada teras pertama. Dari segi waktu pemahatan, relief cerita Ramayana di Candi Prambanan dibangun pada abad IX, sedangkan di Candi Panataran abad XIV (Harmaji, 2006:101102). Sedangkan konsep mengenai kepemimpinan harus selalu dikaitkan dengan tiga hal penting, yaitu: kekuasaan, kewibawaan, dan kepemimpinan (Kartono, 2004). Sedangkan Efendi (1996) menyatakan bahwa kepemimpinan menunjukkan proses kegiatan seseorang dalam memimpin, membimbing, mempengaruhi atau mengontrol pikiran, perasaan atau tingkah laku orang lain. Tedjowulan (dalam Azhar, 2011), falsafah Tri Bata memiliki tiga prinsip, yaitu: 1) rumongso melu handarbeni (merasa ikut memiliki); 2) wajib melu hangrungkebi (wajib ikut membela dengan iklas); 3) mulat sariro hangrasa wani (mawas diri dan memiliki sifat berani untuk kebenaran).

Astha Brata berasal dari kata Astha yang mempunyai arti delapan dan Brata yang mempunyai arti laku atau tindakan atau upaya yang harus dilakukan. Maka Astha Brata adalah delapan nasihat dari Rama yang disampaikan oleh Wibisana sebagai pengganti kepemimpinan Rahwana di Alengka, delapan nasihat tersebut merupakan nilai-nilai yang harus diterapkan seorang pemimpin agar sesuai dengan citra kepemimpinan (Suyami, 2008). Ajaran Astha Brata diambil dari naskah kuno yaitu naskah Sansakerta India Kuno dan ditulis kembali dalam Kakawin Ramayana sekitar tahun 856 Masehi dan digubah dalam Serat Rama oleh Yasadipura I abad ke-19. Jadi dapat disimpilkan bahwa Astha Brata adalah karya sastra hasil budaya masa lalu dari Kakawin Ramayana, kemudian Kakawin Ramajarwa, sampai pada pakem pedalangan dan lakon carangan (Clank, 2008: 152).

Muatan nilai yang bisa diambil dari ajaran Astha Brata yaitu 1) Surya atau matahari artiya seorang pemimpin yang keberadaannya dibutuhkan oleh banyak orang, mampu mengatasi berbagai masalah dan kesulitan yang dihadapi oleh bawahannya, 2) Bawana atau bumi yang mempunyai makna seorang pemimpin hendaknya mengayomi dan melindungi bawahan dan masyarakatnya, 3) Candra atau bulan, pemimpin memiliki sifat-sifat menyenangkan bila dipandang, memperlakukan manusia sama seperti ia diperlakukan 4) Kartika atau bintang, pemimpin mempunyai sifat bintang yang dapat menentukan arah di waktu malam, pemimpin yang memiliki pandangan jauh kedepan, memberi sumber inspirasi, mempunyai cita-cita yang tinggi, dan menjadi tumpuan harapan atas visi, misi dan tujuan yang dibangun bersama, 5) Tirta atau air, pemimpin selalu mempunyai sifat seperti air yang selalu mengalir menyesuaikan tempat, sama hal nya dengan seorang pemimpin yang harus pandai beradaptasi dengan lingkungan sekitar, 6) Maruta atau angin, pemimpin memiliki sifat lembut seperti angin dan sifat yang menyejukkan, harmonis, dan menyegarkan, 7) Dahana atau api, mempunyai makna panas dan dapat membakar, artinya seorang pemimpin harus mampu memberi semangat positif, memberi motivasi, dan memberi inovasi kepada bawahan dan masyarakat, 8) Samodra atau lautan, sifat yang luas melebihi daratan, seorang pemimpin hendaknya memiliki wawasan yang luas, berjiwa lapang, dan mudah memaafkan kesalahan orang lain (Sunarni, 2015). 
Pembahasan mengenai kepimpin, saat ini bisa dikatakan bangsa Indonesia mengalami krisis pemimpin, fakta dilapangan menunjukkan kasus korupsi semakin hari semakin meningkat, hal ini dibuktikan dengan adanya penyelewengan kekuasaan. Ketika pemimpin yang awalnya mencitrakan diri sebagai kandidat yang pantas dipilih dengan mengemban amanah rakyat, namun ketika terpilih sikap tanggungjawab seolah telah sirna, hal ini merupakan salah satu penyakit kepemimpinan yang sangat bahaya bila pemimpin hanya mencari keselamatan diri sendiri atau safety player (Umar, 2013).

Kasus korupsi tidak luput dari kota kecil bernama Nganjuk, kasus korupsi berupa jual-beli jabatan yang dilakukan oleh bupati Nganjuk terhitung dua kali berturut-turut. Kasus yang pertama Bupati nonaktif Taufiqurrahman tahun 2015 dengan dugaan melakukan gratifikasi dua rekanan kontraktor di Kabupaten Nganjuk, Taufiqurrahmna menerima uang suap sebesar Rp. 299 DI Hotel Borobudur, Jakarta Pusat, kasus kedua kalinya penerimaan dana terkait mutasi, promosi jabatan, dan beberapa free proyek di Kabupaten Nganjuk pada tahun 2016-2017. Dalam kasus tersebut dugaan penerima suap yaitu Taufiqurahman Bupati Nganjuk, Ibnu Hajar Kepala Dinas Pendidikan dan Kebudayaan Kabupaten Nganjuk, dan Suwandi Kepala SMPN 3 Ngronggot Kabupaten Nganjuk dan pemberi suap yaitu Mokhammad Bisri Kepala Bagian Umum RSUD Kabupaten Nganjuk dan Harjanto Kepala Dinas Lingkungan Hidup Kabupaten Nganjuk.

Berdasarkan Undang-Undang Republik Indonesia Nomor 31 Tahun 1999 tentang pidana korupsi, kasus korupsi dapat dipidana penjara seumur hidup atau pidana penjara paling singkat empat tahun dan paling lama 20 tahun dengan denda paling sedikit 200 juta rupiah dan paling banyak satu milliar rupiah. Kasus yang sama juga dialami oleh Bupati Nganjuk masa periode 2018-2023 Novi Rahman Hidayat dengan dugaan tindak pidana jual-beli jabatan di lingkungan Pemkab Nganjuk. Dalam dakwaan yang dibacakan oleh Jaksa Penuntut Umum Andie Wicaksono, Novi didakwa atas menyalahgunaan kekuasaan terkait seleksi pengisian perangkat desa. Terdakwa tidak melaksanakan kewajiban sebagai Bupati Nganjuk dalam seleksi pengisian perangkat desa dengan tidak menerapkan prinsip tata pemerintahan yang bersih dan baik. Terdakwa diduga tidak melaksanakan prinsip tata pemerintahan yang bersih dan baik dengan pamrih dan mengharap imbalan dari kepaka desa (Kades) melalui camat yang ada diwilayahnya saat melaksanakan pengisian seleksi perangkat desa. Terdakwa selaku Bupati Nganjuk memaksa para kepala desa yang wilayahnya mengadakan seleksi perangkat desa melalui camat untuk memberikan uang masing-masing sebesar 15juta. Dalam kasus tersebut Novi didakwa dengan pasal 12 huruf e UU No 31 Tahun 1999 sebagaimana diubah dengan UU No. 20 Tahun 2001 Tentang Perubahan atas UU No 31 tahun 1999 tentang pemberantasan Rindak Pidana Korupsi.

Dari dua contoh di atas dapat diketahui bahwa kepimimpin di Kabupaten Nganjuk belum menerapkan konsep kepemimpinan Jawa yaitu ajaran Astha Brata. Pertama dalam ajaran Astha Brata seorang pemimpin harusnya tidak gila harga atau sifat pemimpin yang harusnya keberadaannya dibutuhkan orang lain, ketika para calon perangkat desa ingin melakukan tes seleksi maka pemimpin harusnya bekerja sesuai koridornya.

\section{SIMPULAN}

Untuk mewujudkan citra pemimpin yang baik di masa depan untuk Kabupaten Nganjuk alangkah bijaksana jika semua perangkat pemegang amanah mempunyai sikap yang terdapat pada ajaran Astha Brata, ajaran ini merupakan ajaran meninggalan masa Hindu-Budha di Indonesia, walaupun terbilang ajaran lama, namun dapat dikatakan bahwa ajaran ini masih sangat relevan digunakan dan diterapkan pada abad 21 ini, untuk memperbaiki citra Kabupaten Nganjuk perlu diadakan kerjasama semua elemen mengupayakan menghentikan tindakan tidak terpuji yang 
pernah dilakukan oleh beberapa pejabat, jangan sampai kasus korupsi dan penyalahgunaan jabatan menjadi budaya di kawasan Kabupaten Nganjuk.

\section{DAFTAR PUSTAKA}

Azwar, S. (2015). Sikap Manusia: Teori \& Pengukurannya. Yogyakarta: Pustaka Pelajar.

Chaniago, Aspizain. (2017). Pemimpin dan Kepemimpinan: Pendekatan Teori dan Studi Kasus. Jakarta Pusat: Lentera Ilmu Cendekia.

Clank, M.A. (2008). Wayang Mbeling: Sastra Indonesia Menjelang Akhir Orde Baru.

Efendi, Usman. (2014). Asas Manajemen. Jakarta: Rajawali.

Endraswara, Suwardi. (2013). Falsafah Kepemimpinan Jawa: Butir-Butir Nilai yang Membangun Karakter Seorang Pemimpin Menurut Budaya Jawa. Yogyakarta: Narasi.

George, R Terry. (2014). Dasar-Dasar Management. Penerjemah G.A Ticoalu. Jakarta: bumi aksara.

Hamzah Zakub, Menuju Keberhasilan. Manajemen dan Kepemimpinan. Bandung: CV Diponegoro.

Haryono, Siswoyo. (2015). Intisari Teori Kepemimpinan. Bekasi: Intermedia Personalia Utama.

Kartodirdjo, Sartono. (2004). Teori Kepribadian. Bandung: Angkasa.

Nawawi, Hadari. (2006). Kepemimpinan Mengefektifkan Organisasi. Yogyakarta: UGM Press.

Sunarni. Menguak Kembali Falsafah Kepemimpinan Ala Jawa (Refleksi Untuk Masa Depan), Jurusan Administrasi Pendidikan, Fakultas IImu Pendidikan, Universitas Negeri Malang.

Suwarni. (2010). Citra Pemimpin Bangsa dalam Pustaka Jawa Post on, Universitas Negeri Surabaya, dibaca: 1582 kali.

Suyami. (2008). Konsep Kepemimpinan Jawa Dalam Ajaran Sastra Centha dan Astha Brata. Yogyakarta: Kepel Press.

Umar, Bambang Widodo. (2013). "Krisis Kepemimpinan”, Legalitas, 4(1): 7-21. 